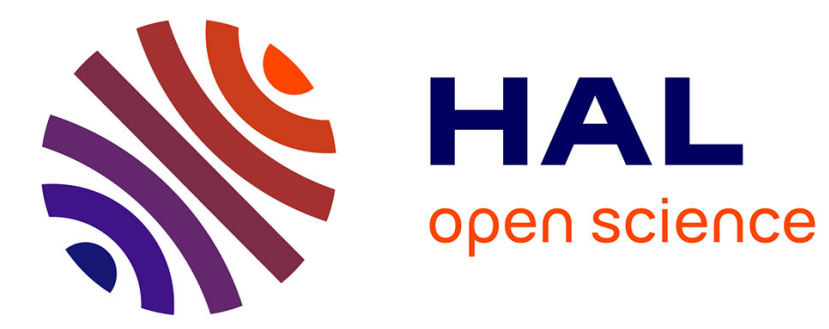

\title{
SCATTERING OF CHARGE-CARRIERS BY DISLOCATIONS
}

\author{
E. Gerlach
}

\section{To cite this version:}

E. Gerlach. SCATTERING OF CHARGE-CARRIERS BY DISLOCATIONS. Journal de Physique Colloques, 1979, 40 (C6), pp.C6-47-C6-49. 10.1051/jphyscol:1979610 . jpa-00219026

\section{HAL Id: jpa-00219026 https://hal.science/jpa-00219026}

Submitted on 1 Jan 1979

HAL is a multi-disciplinary open access archive for the deposit and dissemination of scientific research documents, whether they are published or not. The documents may come from teaching and research institutions in France or abroad, or from public or private research centers.
L'archive ouverte pluridisciplinaire HAL, est destinée au dépôt et à la diffusion de documents scientifiques de niveau recherche, publiés ou non, émanant des établissements d'enseignement et de recherche français ou étrangers, des laboratoires publics ou privés. 


\section{SCATTERING OF CHARGE-CARRIERS BY DISLOCATIONS}

E. Gerlach

I. Physikalisches Institut der RWTH Aachen, F.R.G.

Résumé.- La méthode de "l'énergie perdue" est utilisée pour traiter la diffusion dc et dynamique par des dislocations.

Abstract.- The energy-loss-method is used to treat dc and dynamical scattering by dislocations.

1. Introduction. - A common method to study irregularities in crystals such as dislocations, point defacts etc... is to investigate transport coefficients $/ 1-3 /$. These, however, are integral quantities averaging over a distribution of the electrons in momentum space. Information about the scattering mechanism, however, is retained, if parameters as the temperature $T$, the frequency $w$ or a magnetic field can be varied.

In a crystal dislocation lines are arranged in accordance with the crystal structure thus forming a geometrically complicated scattering system. In addition, the scattering potential usually is strongly affected by free carriers. Thus in order to describe these phenomena we need a transport theory which is able to cover the following physical situations:

a) Geometrically complicated scattering centers

b) Screening by free carriers

c) Dynamical ( $\omega$-dependent) transport problems

d) Plasmon excitation

e) External magnetic fields

Further, of course, the theory should be conceptually and mathematically simple.

2. The "Energy-loss" method. - A transport theory fulfilling these requirements has recently been studied in a wide range of semiconductor physics. (For a review see /3/). In order to illustrate the idea of this method we consider the scattering by a point charge of density $\rho_{f}$.

We start from an energy loss arrangement in which a charged particle is moving with constant velocity $\underline{v}$ through a solid (Fig. 1).

The energy loss of the particle is given by a simple functional $F$ of the moving charge density $\rho_{f}$, of its velocity $\underline{v}$ and the dielectric properties $\varepsilon(\underline{k}, \omega)$ of the solid /4/

$-\frac{d W}{d t}=F\left[\rho_{f}, \underline{v}, \varepsilon(\underline{k}, \omega)\right]$

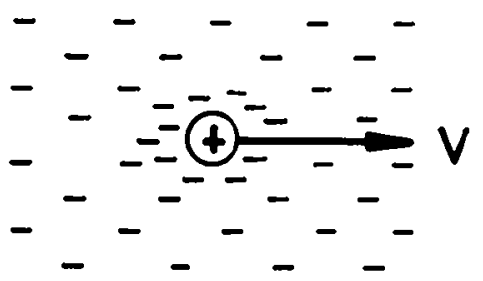

Fig. 1 : Moving screened point charge in an electron gas.

Returning now to the transport oroblem, we reverse the frame of reference, that is we consider the point charge to be fixed in space and pull the electron gas with the velocity $\underline{v}$ over it. The scattering of the electrons leads to a Joule heat $\underline{j} \cdot \underline{E}$ which is identical to the energy loss calculated above

$-N \frac{d \cdot N}{d t}=\underline{j} \cdot \underline{E}=\rho(n \text { e } v)^{2}$

( $N$ concentration of scattering centers, here assumed to be independent of each other, $\rho$ resistivity, $n$ carrier concentration). From this identification the dc resistivity of the carriers scattered by point charges of density $\rho_{f}$ is immediately obtained. (The functional $F$ is an integral. The drift velocity $v$ is cancels). The subtleties of the scattering are contained in the wavevector- and frequency dependent dielectric function of the electron gas which we consider in the Lindhard-(RPA)-approximation /3/,/5/ (Fig. 2). This can easily be extended to non-sperical cases.

In the theory described so far no particular use was made of that $\rho_{f}$ was a point charge. The quantity can be taken to be a charged line or a dipole line representing simple models of dislocations or $\rho_{f}$ may be any complicated scattering system. Screening effects are automatically included by the function $\varepsilon(\underline{k},(1))$.

Further, instead of considering an energy-los 
arrangement with constant velocity $\underline{v}$ one may study an oscillating charge density $\rho_{f}$ thus leading to a complex frequency dependent resistivity, which also includes plasmon-effects.
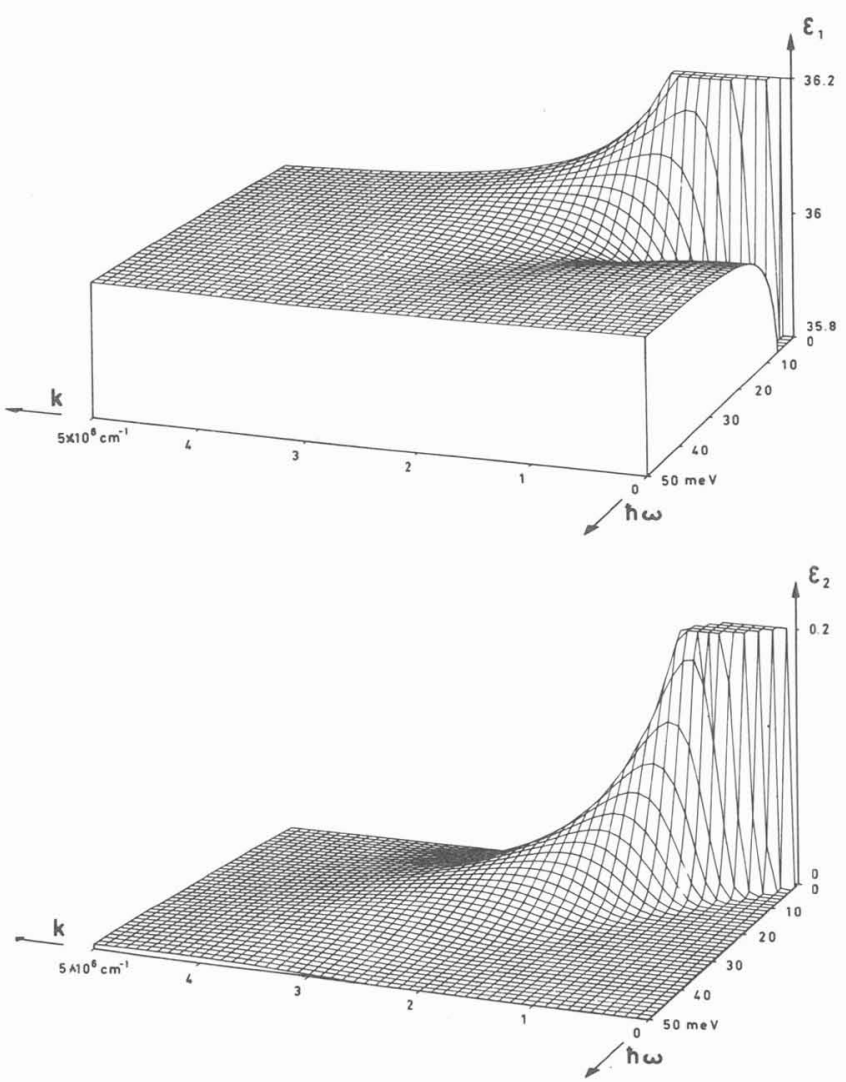

Fig. 2 : Real and imaginary part of the Lindhard dielectric function for a model semiconductor

$\left(\mathrm{n}=10^{15} \mathrm{~cm}^{-3}, \mathrm{~m}^{*}=0,2 \mathrm{~m}_{0}, \varepsilon_{\mathrm{L}}=36, T=80 \mathrm{~K}\right)$

For a charged monopole line and a dipole line, respectively, the results are given by $/ 6 /$

$\rho_{m}(\omega)=\frac{i q^{2} N_{m}}{4 \pi \frac{\varepsilon_{0}}{\varepsilon^{2} n^{2} \omega}} \int_{0}^{\infty} d k k\left[\frac{1}{\varepsilon(\underline{k}, \omega)}-\frac{1}{\varepsilon(\underline{k}, 0)}\right]$

( $q$ charge per length, $N_{m}$ density of monopole lines)

$\rho_{d}(\omega)=\frac{i r^{2} N_{d}}{16 \pi \varepsilon_{0} n^{2} \omega} \int_{0}^{\infty} d k k^{3}\left[\frac{1}{\varepsilon(\underline{k}, \omega)}-\frac{1}{\varepsilon(\underline{k}, 0)}\right]$

$(\gamma=$ dipole moment per length and elementary charge, $\mathrm{N}_{\mathrm{d}}$ density of dipole lines). These expresssions, of course, have to be completed be a term originating from the inertia of the electrons $\left(\omega_{\mathrm{p}}\right.$ plasma frequency)

$\rho_{i}=-i \frac{\omega}{\varepsilon_{0} \omega_{p}^{2}}$

The dc-limit is immediately obtained by taking the limit $\omega \rightarrow 0$.
The interaction of two neighboring dislocation lines was studied in reference $/ 7 /$.

We now list a number of results obtained for scattering by monopole lines and by dipole lines.

a) charged monopole line $/ 3 /, 16 /$

Nondegenerate carrier distribution $\rho(\omega=0)=\frac{\Pi^{1} / 2 N_{m} q^{2} m^{* 1 / 2} g(p)}{2^{9} / 2\left(n \varepsilon \varepsilon_{0}\right)^{3} / 2 \text { e kT }}$

$g(p)=(1+2 p) e^{p} \operatorname{erfc} p^{1 / 2}-2 p^{1 / 2} / \pi^{1 / 2}$

$p=\hbar^{2} k_{D H}^{2} / 8 m^{*} k T ; k_{D H}^{2}=e^{2} n / \varepsilon_{L} \varepsilon_{0} k T$

$\varepsilon_{L}$ dielectric constant of the host material. Degenerate carrier distribution

$$
\begin{aligned}
& \rho(\omega=0)=\frac{N_{m} q^{2} m^{*} \bar{g}\left(p^{\prime}\right)}{8 \varepsilon_{L} \varepsilon_{0} n^{2} e^{2} \hbar} \\
& \bar{g}\left(p^{\prime}\right)=\frac{1}{p^{T}} \arctan p^{\prime}-\frac{1}{1+p^{12}} \\
& p^{\prime}=2 k_{F} / k_{F T} \quad ; k_{F T}^{2}=\left(m^{*} e^{2} / h^{2} \varepsilon_{L} \varepsilon_{0}\right)\left(3 n / \pi^{4}\right)^{1} / 3 \\
& \rho^{\prime}(\omega \rightarrow \infty) \sim \omega^{-2}
\end{aligned}
$$

b) Dipole line $/ 3 /, / 6 /$, nondegenerate

$\rho_{\perp}(a=0)=\frac{\pi^{1 / 2} e^{3} \gamma^{2} N_{d} m^{*} 1 / 2}{2^{1 / 2}\left(\varepsilon_{L} \varepsilon_{0}\right)^{5 / 2} n^{1 / 2}(k T)^{2}}\left(-\frac{\partial g(p)}{\partial p}\right)$

(dipole moment perpendicular to current) $\rho_{1 s}=3 \rho_{\perp}$

$\rho^{\prime}(\omega \rightarrow \infty) \sim \omega^{-1}$

Figures 3 and 4 show the scattering of free electrons by a monopole line and a dipole line, respectively, for the model semiconductor of figure 2 . The plasma resonance at $\omega_{p} / \sqrt{\varepsilon_{L}}$ separates a constant behavior from a power law.

The method has also been successfully applied to deformation potential scattering and to piezo electric scattering $/ 3 /$.

If the dislocations are arranged in a layer structure the dynamical resistivity under certain conditions shows geometrical resonances for frequencies which correspond to Bragg-reflection, of the free electrons and of the plasmon, respectively, $\rho^{\prime}(\omega \rightarrow \infty) \sim \omega^{-5 / 2}$ (Gerlach E, Paier $K$, unpublished).

In conclusion we would like to mention that a large number of the results obtained by the energy loss method have been successfully applied to identify the various types of scattering centers in semi conductors $/ 3 /$. 


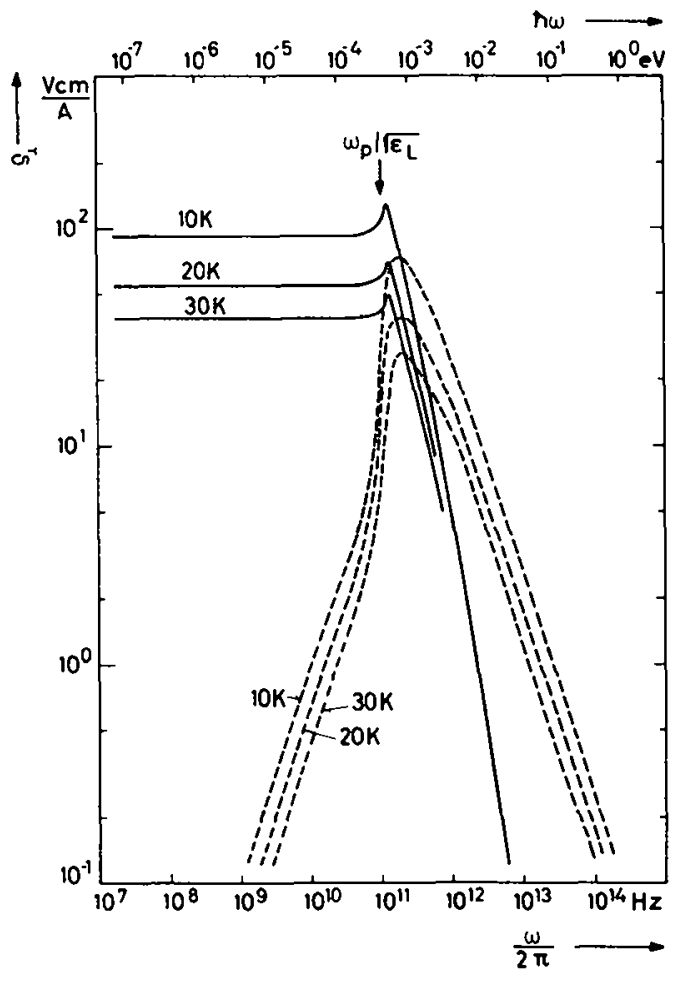

Fig. 3 : Dynamical resistivity for scattering by a monopole line versus frequency (- real part, --imaginary part).

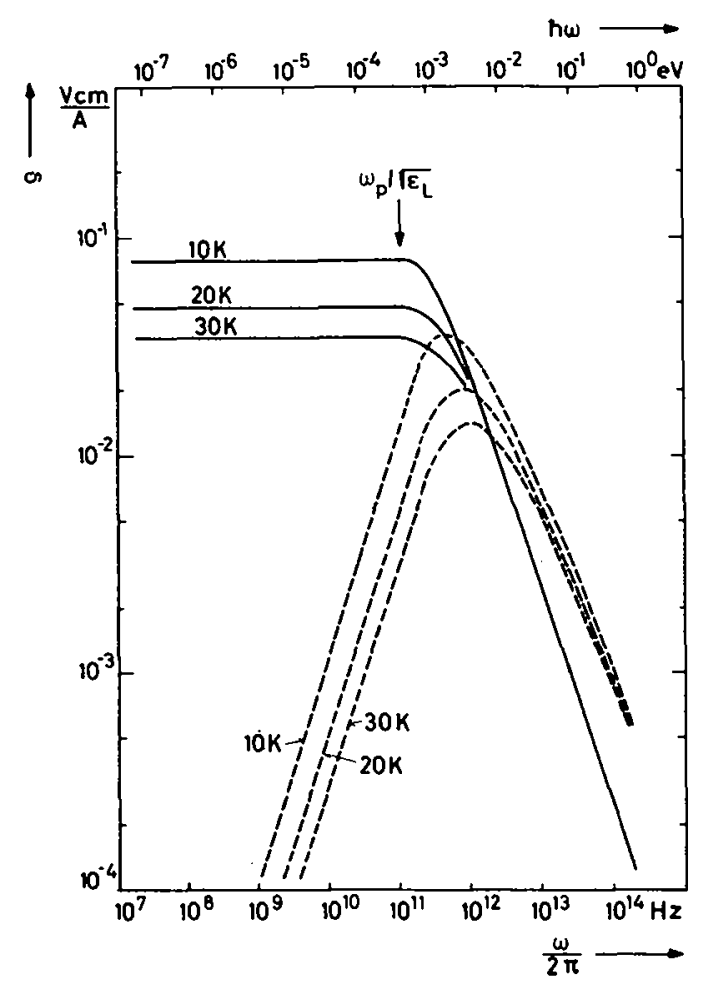

Fig. 4 : Dynamical resistivity $\rho_{\perp}$ for scattering by a dipole line versus frequency (- real part, --- imaginary part)

\section{References}

/1/ Düster, F. and Labusch, R., Phys. Status Solidi (b) 60 (1973) 161 .

/2/ Pödor, B., Phys. Status Solidi 16 (1966) K 167.

13/ Gerlach, E. and Grosse, P., Festkörperprobleme, Advances in Solid State Physics, Volume XVII, p. 157, J. Treusch ed, Vieweg, Braunschweig (1977)

14/ Pines, D., Elementary Excitations in Solids (W. A. Benjamin, New York) 1964, p. $126,144$.

15/ Lindhard, J., Kgl. Danske, Videnskab Selskab., Mat. Fys. Medd 28, No. 8 (1354)

16/ Gerlach, E. and Rautenberg M., Phys. Status Solidi (b), 67 (1975) 519.

17/ Doukhan, J.C., Drope, R., Farvacque, J.L., Gerlach, E., Grosse, P., Phys. Status Solidi (b) 64, (1974) 237. 